Voix et Images

voixetimages

\title{
Monique Bosco, l’iconoclaste
}

\section{Gloria Escomel}

Volume 9, numéro 3, printemps 1984

Monique Bosco

URI : https://id.erudit.org/iderudit/200479ar

DOI : https://doi.org/10.7202/200479ar

Aller au sommaire du numéro

\section{Éditeur(s)}

Université du Québec à Montréal

\section{ISSN}

0318-9201 (imprimé)

1705-933X (numérique)

Découvrir la revue

\section{Citer cet article}

Escomel, G. (1984). Monique Bosco, l'iconoclaste. Voix et Images, 9(3), 47-54. https://doi.org/10.7202/200479ar d'utilisation que vous pouvez consulter en ligne.

https://apropos.erudit.org/fr/usagers/politique-dutilisation/ 


\title{
Monique Bosco, l'iconoclaste
}

\author{
par Gloria Escomel
}

On ne pardonne aux iconoclastes que s'ils font partie d'un troupeau. Ou s'ils ne détruisent que les idoles déjà condamnées par la mode. Jamais s'ils s'attaquent pêle-mêle aux icônes à peine découvertes et à celles qui sombraient dans l'oubli. Encore moins si ces iconoclastes sont des femmes. Monique Bosco est de celles-là, toujours à contre-temps, contre le temps, tout contre, aussi, mais à rebrousse-temps, à dépasse-temps...

Le Portrait de Zeus peint par Minerve en est un très bon exemple. Car, brouillant volontairement toutes les pistes, il ne donne pas prise aux critiques idéologiques, ni à aucune sorte de récupération.

Je me suis creusé et inventé des labyrinthes, dignes des temps anciens,

ou je me suis perdue, pendant des années (p. 179). ${ }^{1}$

C'est dans ces labyrinthes qu'elle nous entraîne et nous égare, sur l'écume d'une prose qui a le rythme des marées, flux et reflux, murmure de la vague sur les galets, s'amplifiant et s'amenuisant selon la force du vent, la profondeur de la houle; le calme plat de la peine et de l'abattement, ou le souffle déchaîné des révoltes:

Je m'enfuis, moi, pour ne pas voir ce printemps sanglant, trop précocement beau.

J'ai réussi à m'échapper.

Comme il est éclatant et honteux à la fois de toujours déserter aux heures de malheur extrême.

Je ne puis voir ces horreurs que je connais, de si près, depuis l'origine.

Loi du fils. 
Lois du père.

Tant d'offenses.

Tant de crimes.

Réglez cela, entre vous (p. 2).

Iconoclaste: on admet cette disposition typographique dans des poèmes, des proses poétiques... ou dans la «nouvelle écriture».

Et si la «fiction» de Monique Bosco a souvent le rythme ou les harmonies de la prose poétique, tout en se présentant comme un récit, mais sans être un roman, ni des vers, elle n'est pas non plus rattachée à la nouvelle écriture, dont on aurait bien du mal, d'ailleurs, à trouver une quelconque définition. La phrase, hormis quelques fantaisies de ponctuation et d'effets purement typographiques, reste classique, le jeu sur le signifiant, beaucoup plus modéré que dans Charles Lévy, m.d. Aucune acrobatie de style, peu de jeux sémantiques. Une parole translucide, se déployant comme vague irisée par les sables du temps, une phrase obsédante et répétitive, comme ce mouvement d'avance et de recul de la marée montante.

Le Portrait de Zeus peint par Minerve est celui d'un dieu, d'un père, d'un homme qui agonise interminablement, sous le regard tour à tour révolté, incrédule, méprisant, revendicatif, vengeur, apitoyé, désarçonné, haineux, passionné et tendre d'une Minerve s'interrogeant sur la mort des dieux, mais aussi sur la vie sans le Père.

Dans ce portrait, la silhouette de Zeus est campée à travers celles de César, Franco, Tito, éminemment associée au pouvoir, comme il se doit; mais Zeus est déjà condamné à mort par son successeur, par son fils (ou sa fille?):

Méfie-toi. Méfie-toi des ides de mars.

César, ne t'endors pas.

Et toi, Brutus?

Hélas, Brutus, qu'il est sauvage et dur d'accomplir la loi. (...) Il est écrit que César ne goûtera pas à une autre saison de pouvoir et de force. Son règne doit s'achever. C'est inscrit. Tous les augures l'ont annoncé.

Mauvais fils.

Faux patriote (p. 1).

...

Zeus est mort.

Je ne peux le taire plus longtemps.

Je les regarde maintenir en fausse vie tous les

Franco, tous les Tito de ce bas monde (p. 4).

Cette perspective résolument anachronique, qui insiste sur ce décalage entre la mythologie grecque (Zeus - Héra) et la romaine (Minerve), puis sur 
l'histoire (César, Franco, Tito), la littérature (personnages de la guerre de Troie, le roi Lear, l'ogre et le Petit Poucet,) l'univers biblique (Noé, Job, le Roi des Rois), ou la société contemporaine (tramways, avions, dépliants touristiques de la Vallée de la mort, pigeons sur le balcon), dont Monique Bosco a déjà usé, dans une moindre mesure, dans New Medea, et qui n'est certes pas nouvelle dans le traitement des personnages mythologiques de la littérature contemporaine, va cependant beaucoup plus loin, parce qu'elle transgresse les codes établis.

La démystification de Zeus, son agonie, sa mort seraient-elles annonciatrices de la fin du règne patriarcal tout entier? On pourrait le croire.

Je te surveille, Zeus.

Parfois ma haine est la plus forte.

Pourquoi, à toi seul, les joies du cirque sontelles permises?

Dompteur.

Dominateur (p. 40).

Zeus, qui es-tu pour te croire irremplaçable

Qui suis-je pour te croire

Partageant l'illusion

Que le monde s'arrêtera de tourner

Quand ton coeur cessera de battre (p. 63)

Mais à peine croit-on reconnaître une thématique déjà familière aux féministes que l'illusion est ébranlée, par une interrogation et par d'innombrables protestations de désespoir.

Suis-je fille de mon père, créé pour l'honorer et le chanter, fidèle vestale, toute entière vouée à le célébrer - force, puissance et bonté inestimable - ou le fils de sa création, son égal, son futur remplaçant sur cette terre (p. 25)?

...

Zeus y a passé comme les autres.

Longtemps, je me suis bercée de l'illusion qu'il était assez furieux et forcené pour lui résister, à jamais. Assez longtemps, du moins, pour que je ne voie plus, de mes yeux, le corps terrassé de la divinité.

Celui qui donne la vie n'a pas le droit de se plier ainsi, sous la fatale loi.

Zeus, le père glorieux, se devait à sa postérité (p. 4).

L'ambivalence, certes, est normale. Zeus est peut-être un dieu, un mythe; mais il est aussi un prête-nom, seul subterfuge possible pour parler 
de la mort d'un père; n'étant pas qu'un symbole, il suscite à la fois les fantasmes éveillés par les dieux et les sentiments suscités par un père mourant.

Et que ferait-on en 1983, à l'heure où l'on découvre le lien viscéral de la fille avec sa mère, d'une Minerve à contre-courant, qui se dit fière d'être née hors $d u$ ventre féminin, échappant à la boucherie de cette sortie des ténèbres, sang et immondices mêlés ( $p$. 4), fille sans mère, même lorsqu'elle est revendiquée par Héra? Héra, qui pour démystifier la «fable» de sa naissance, contraint Minerve à assister à un accouchement, pour lui montrer comment naissent les enfants, Héra, qui en dépit de toute culture mythologique l'appelle «ma fille»... Minerve a beau se raconter la merveilleuse histoire de sa naissance, à laquelle personne ne veut croire, elle sent bien qu'elle s'en conte et s'en est fait conter.

Iconoclaste: Minerve-Athéna était pourtant un merveilleux mythe à investir de toutes les revendications féministes: déesse de la raison, de la sagesse, de la force, conseillère des dieux... mais non. La Minerve de Monique Bosco est faible, folle, fille aspirant au sort commun des femmes fragiles, qu'elle méprise pourtant; sans être vierge, les hommes redoutent de la féconder. Elle avoue:

Oui, j'ai aimé ce repaire du père.

Loin du monde.

Protégée par mon infirmité, ma nullité.

Je ne voulais pas entrer dans ce monde double

et charnel,

ces liens du sexe et du coeur, ces passions absurdes et éphémères.

Les filles de mon age me semblaient frivoles.

(...)

Je les regardais faire, médusée, envieuse peutêtre (p. 99).

Et pourtant, Minerve - ou plutôt Athéna - est née d'une tentative originale de Zeus pour réaliser la fusion des sexes, «la fusion du tout et la distinction des parties». La mère, Phanès-Métis, «premier-né et premier géniteur mâle et femelle», déjà proche de l'androgyne, donc, fut avalée par Zeus au moment où elle allait accoucher d'Athéna, non seulement pour transformer la grossesse de la femme en «une grossesse masculine où se dit la perfection du commencement», mais aussi pour éviter la naissance d'un fils appelé à le détrôner. ${ }^{2}$ De cette signification du mythe, Monique Bosco retient quelques éléments, curieusement transformés.

Dieu double et trouble.

Méprisant les femmes ordinaires, tout en leur enviant sournoisement ce don rare et pourtant si répandu de pondeuses-couveuses-nourrices. Voilà donc Zeus père-mère. 
Il s'accouche, tel Adam, d'une femme née de sa propre chair (p. 87).

L'être qui doit naître de Zeus, si l'on en croit le «s'accouche», c'est un autre Zeus, mais la comparaison avec Adam n'augure rien de bon pour cette femme née de sa propre chair... Par ailleurs, si Zeus est dit «double», père et mère, Minerve n'est pas pour autant cet être total, androgyne, que certaines «amazones» pourraient espérer; elle aime trop les hommes, tout en les méprisant, pour rêver d'instituer une société purement féminine; elle se plaît en compagnie de ses soeurs, mais elles ne séduisent pas ses sens; enfin, elle souffre de ne pas avoir d'enfants et se plaint d'être «Enfant monstre. Ni fille ni garçon, ni créature de mer ni oiseau de ciel et d'air) (p. 50). Par ailleurs, elle va jusqu'à nier la fécondation et la grossesse dé sa mère: Minerve n'est pas née d'une femme comme les autres. Il n'y eut pas de coeur de la nuit/pas de semence/pas d'oeuf où se loger, se nicher" (p. 76).

En évacuant aussi complètement l'image de la mère, remplacée par Héra, «la belle-mère», Minerve refuse aussi celles que l'épouse de Zeus, devenue veuve, métamorphosée par l'absence dé l'homme; lui désigne comme ses soeurs, les femmes d'une ère nouvelle; elle les refuse, non plus par mépris, mais parce qu'il est trop tard pour celle qui a été créée pour adorer et servir Zeus-le-père. Et ce sont justement ces passages, pathétiques, exprimant le malaise de toute une génération en porte-à-faux, qui placent «l'iconoclaste» en marge de toute nouvelle idéologie, gardant intacte la révolte contre l'ancienne loi patriarcale. Ce «nevermore» dont elle faisait l'anagramme de Minerve, s'exprime ici avec une totale et impardonnable sincérité:

Elles ne suivent plus personne, elles.

Aucun dieu, aucun héros ne leur sert de modele.

Même Héra est gagnée par la contagion. (...)

Car c'est un autre jour et un autre règne qui commencent.

Je veux bien les croire.

Leur tranquille assurance réussit à me convaincre, à me persusader de leur monde de merveilles.

Plus de jalousie, de rivalités meurtrières,

Une aimable complicité les unit, toutes ensemble.

"Vois tes soeurs».

Je les vois, en effet, gracieuses et jeunes, solides et indépendantes.

Elles jouent sans s'effaroucher d'aucun interdit ou tabou. (...)

Je suis Minerve depuis trop longtemps.

$J$ 'appartiens à un autre siècle; à un autre temps.

Époque archaíque. 
Nulle révolution ne fera tomber ces forteresses, ces barricades (pp. 174-175).

Tout ce qui aurait pu s'inscrire dans le courant d'un dogme naissant, féministe radical, par exemple, est évacué. Mais que le partriarcat ne s'en réjouisse pas! Cette féministe de la première heure ne se renie pas pour autant. Toutes les valeurs patriarcales ont été démystifiées; à travers le lamento de Minerve, il ne reste d'elles que le rêve que Zeus et ses semblables avaient voulu insuffler au monde, rêve dont il ne reste rien, avec l'agonie et la mort de Zeus.

Zeus est malheureux, impuissant.

Je t'ai choisi.

Lucidement, comme seule une enfant peut le faire

dans toute la force de la passion et de l'amour (p. 122).

$\dddot{O}$ monde des hommes.

Ma stupeur est grande, je l'avoue.

Comme ce monde est petit, étriqué.

Tout vous cache le soleil, vous porte ombrage.

Jamais on ne rend assez d'hommages

à votre dignité, votre virilité (p. 149).

Cette pitié, cette lucidité n'ont rien de bien flatteur, en vérité. En vérité? Mais laquelle? Aucune, justement, mais une recherche éperdue, une recherche qui s'essouffle, tourne en spirale, acquiert quelques certitudes deci de-là.

Ainsi, après la traversée de la Vallée de la Mort, où Minerve parcourt les déserts de sable, de poussière et de sel, seuls vestiges des labeurs de la terre, seule trace d'un ancien océan, saisie par la beauté de l'absolue dévastation, comprenant qu'elle doit se détourner de cette fascination, elle revient aux palmeraies, à l'oasis. À travers l'univers touristique, les dépliants publicitaires, les cartes postales, les images de la Vallée de la Mort, elle se sent trahie. Ces images faussent la réalité du lieu de désolation, le souvenir même du cataclysme ancien, «d'avant le temps de Zeus».
J'ai vraiment cru trouver ici une ombre de réponse.
Mais j'ai aussi compris autre chose. Je ne crains point cette mort, vois-tu (p. 118).

Première libération sans doute, mais accepter sa propre mort peut paraître plus simple qu'accepter la mort d'autrui, la mort du père, la mort d'un dieu. Mais cela permet à Minerve d'accepter d'être la fille d'un Dieule-Père auquel on n'a prêté que des fils, jusque-là.

Une seule réaction salvatrice: celle de l'iconoclaste. 
Fille des mythes que Zeus a bâtis, autour de lui et autour d'elle, prisonnière des légendes, Minerve ne sait ni vouloir ni inventer, qui ne tourne autour de Zeus:

Rien à bâtir, à construire.

Détruire, peut-être.

Tous ces clichés anciens.

On pourrait en remplir des albums innombrables.

Quelles images m'ont trompée? (p. 119).

Au bout d'un long travail de démystification, il ne reste à Minerve que lambeaux des anciennes images. Ou plutôt des éclats de miroir qui lui renvoient l'image éparpillée du monde, l'illusion de la réalité, mais par reflet interposé:

Je ne me souviens plus de rien.

Une rêverie peut enfin se faire jour, confuse et précise, par moments.

Comme ces miroirs brisés en éclats minuscules.

Un reflet fidèle s'y inscrit, sous un certain angle.

Sous un autre, seule la distorsion se fait sentir.

Je joue avec ces fragments de vie, de verre:

Avec une infinie patience, en m'y appliquant de

toute mon âme, je réussis ainsi, parfois, à capter la brûlure du soleil levant (p. 176).

Mais cependant, ce dernier jeu de reflets était nécessaire, pour qui était élevée à voir le monde à travers des clichés, pour qui ne peut survivre qu'au prix de leur destruction. Enfin, Minerve pourra dire:

Je suis allée au fond des apparences.

Qui peut se vanter d'avoir été plus loin? (p. 179)...

La contradiction de l'iconoclaste réside évidemment dans son fétichisme. L'image, l'icône est sacrée. La détruire, c'est détruire la divinité manifestée, tout autant que détruire la fausse représentation, l'apparence qui détourne l'être humain de l'essence. Première phase de l'opération à laquelle Minerve a dû se livrer. Toutefois, le paradoxe de l'iconoclaste la réduira à tracer le portrait du dieu disparu (mais un dieu mort est-il encore un dieu, le sacrilège est-il si grand, lorsqu'on ne peint qu'un souvenir, ou plutôt, une radiographie du souvenir?).

Comme les enfants, avec un peu de papier, des crayons de couleur, je peux essayer de tracer son portrait, sur la feuille blanche.

«Portrait de Zeus, peint par Minerve» (p. 179). 
Car ce portrait, tant le destin de Zeus et de Minerve est étroitement lié, est tout autant un portrait de Minerve tracé à travers les images détruites de Zeus et démystifié par Minerve elle-même, double jeu de reflets qui se renvoient l'un l'autre.

Mais, justement parce que Minerve est allée au fond des apparences seule condition pour pouvoir tracer un portrait - qu'elle est allée au bout de la destruction de l'image, pour mieux appréhender l'essence de la réalité, elle peut désormais sortir des profondeurs de la terre et de la nuit:

J'ai tant creusé dans le noir de la nuit,

de la passion sans issue.

J'ai choisi les ténèbres.

Maintenant, peut-être suis-je prête

à affronter la lumière crue

du soleil levant (p. 179)

(...)

Minerve, le monde est grand.

(...) il ne reste plus qu'à déplier les ailes, vaincre

la peur du vide et s'élancer, droit en avant, sans

un regard vers le ciel ou le sol, juste droit en

avant, les yeux enfin ouverts (p. 179).

1. Portrait de Zeus peint par Minerve, Montréal, HMH, 1982, 179 pages.

Toutes les citations étant tirées de cette oeuvre, nous n'indiquerons plus que le numéro de la page entre parenthèses.

2. Dictionnaire des mythologies, (sous la direction de Yves Bonnefoy), Paris, Flammarion, $2 \mathrm{e}$ vol., p. 554, article Zeus. 